\title{
Blood-brain barrier impairment and hypoperfusion are linked in cerebral small vessel disease
}

Citation for published version (APA):

Wong, S. M., Jansen, J. F. A., Zhang, C. E., Hoff, E. I., Staals, J., van Oostenbrugge, R. J., \& Backes, W. $\mathrm{H}$. (2019). Blood-brain barrier impairment and hypoperfusion are linked in cerebral small vessel disease. Neurology, 92(15), E1669-E1677. https://doi.org/10.1212/wnl.0000000000007263

Document status and date:

Published: 09/04/2019

DOI:

10.1212/wnl.0000000000007263

Document Version:

Publisher's PDF, also known as Version of record

Document license:

Taverne

Please check the document version of this publication:

- A submitted manuscript is the version of the article upon submission and before peer-review. There can be important differences between the submitted version and the official published version of record.

People interested in the research are advised to contact the author for the final version of the publication, or visit the DOI to the publisher's website.

- The final author version and the galley proof are versions of the publication after peer review.

- The final published version features the final layout of the paper including the volume, issue and page numbers.

Link to publication

\footnotetext{
General rights rights.

- You may freely distribute the URL identifying the publication in the public portal. please follow below link for the End User Agreement:

www.umlib.nl/taverne-license

Take down policy

If you believe that this document breaches copyright please contact us at:

repository@maastrichtuniversity.nl

providing details and we will investigate your claim.
}

Copyright and moral rights for the publications made accessible in the public portal are retained by the authors and/or other copyright owners and it is a condition of accessing publications that users recognise and abide by the legal requirements associated with these

- Users may download and print one copy of any publication from the public portal for the purpose of private study or research.

- You may not further distribute the material or use it for any profit-making activity or commercial gain

If the publication is distributed under the terms of Article $25 \mathrm{fa}$ of the Dutch Copyright Act, indicated by the "Taverne" license above, 


\section{Blood-brain barrier impairment and hypoperfusion are linked in cerebral small vessel disease}

Sau May Wong, PhD, Jacobus F.A. Jansen, PhD, C. Eleana Zhang, MD, Erik I. Hoff, MD, Julie Staals, MD, Robert J. van Oostenbrugge, MD, and Walter H. Backes, PhD

Neurology ${ }^{\circledR}$ 2019;92:e1669-e1677. doi:10.1212/WNL.0000000000007263

\section{Abstract}

\section{Objective}

To investigate the link between blood-brain-barrier (BBB) permeability and cerebral blood flow $(\mathrm{CBF})$ and the relation with white matter hyperintensities $(\mathrm{WMH})$ in cerebral small vessel disease (cSVD).

\section{Methods}

Twenty-seven patients with cSVD received dynamic susceptibility contrast and dynamic contrast-enhanced MRI to determine $\mathrm{CBF}$ and $\mathrm{BBB}$ permeability (expressed as leakage rate and volume), respectively. Structural MRI were segmented into normal-appearing white matter (NAWM) and WMH, for which a perilesional zone was defined. In these regions, we investigated the $\mathrm{BBB}$ permeability, $\mathrm{CBF}$, and their relation using Pearson correlation $r$.

\section{Results}

We found a decrease in CBF of $2.2 \mathrm{~mL} / \mathrm{min} / 100 \mathrm{~g}(p<0.01)$ and an increase in leakage volume of $0.7 \%(p<0.01)$ per $\mathrm{mm}$ closer to the $\mathrm{WMH}$ in the perilesional zones. Lower CBF values correlated with higher leakage measures in the NAWM and WMH $(-0.53<r<-0.40, p<$ $0.05)$. This relation was also observed in the perilesional zones, which became stronger in the proximity of WMH $(p=0.03)$.

\section{Conclusion}

BBB impairment and hypoperfusion appear in the WMH and NAWM, which increase in the proximity of the $\mathrm{WMH}$, and are linked. Both $\mathrm{BBB}$ and $\mathrm{CBF}$ are regulated in the neurovascular unit (NVU) and the observed link might be due to the physiologic regulation mechanism of the NVU. This link may suggest an early overall deterioration of this unit.

\author{
Correspondence \\ Dr. Backes \\ w.backes@mumc.nl
}

\section{RELATED ARTICLE}

\section{Editorial}

White matter lesions in cerebral small vessel disease: Underperfusion or leaky vessels?

Page 687

From the Departments of Radiology and Nuclear Medicine (S.M.W., J.F.A.J., W.H.B.), Neurology (C.E.Z., J.S., R.J.v.O.), School for Mental Health and Neuroscience (MHeNs) (S.M.W., J.F.A.J., C.E.Z., R.J.v.O., W.H.B.), and Cardiovascular Research Institute Maastricht (CARIM) (C.E.Z., J.S., R.J.v.O.), Maastricht University Medical Centre; and the Department of Neurology (E.I.H.), Zuyderland Medical Centre, Heerlen, the Netherlands.

Go to Neurology.org/N for full disclosures. Funding information and disclosures deemed relevant by the authors, if any, are provided at the end of the article. 


\section{Glossary}

$\mathbf{B B B}=$ blood-brain barrier; $\mathbf{C B F}=$ cerebral blood flow; $\mathrm{CI}=$ confidence interval; $\mathrm{cSVD}=$ cerebral small vessel disease; $\mathbf{D C E}=$ dynamic contrast-enhanced; DSC = dynamic susceptibility contrast; DSI = dynamic scan interval; FLAIR = fluid-attenuated inversion recovery; FOV = field of view; $\mathbf{G M}$ = gray matter; NAWM = normal-appearing white matter; NVU = neurovascular unit; ROI = region of interest; TE = echo time; TI = inversion time; $\mathbf{T R}=$ repetition time; $\mathbf{V C I}=$ vascular cognitive impairment; $\mathbf{W M}=$ white matter; $\mathbf{W M H}=$ white matter hyperintensities.

\section{Partners in crime: Impaired BBB and hypoperfusion in cSVD}

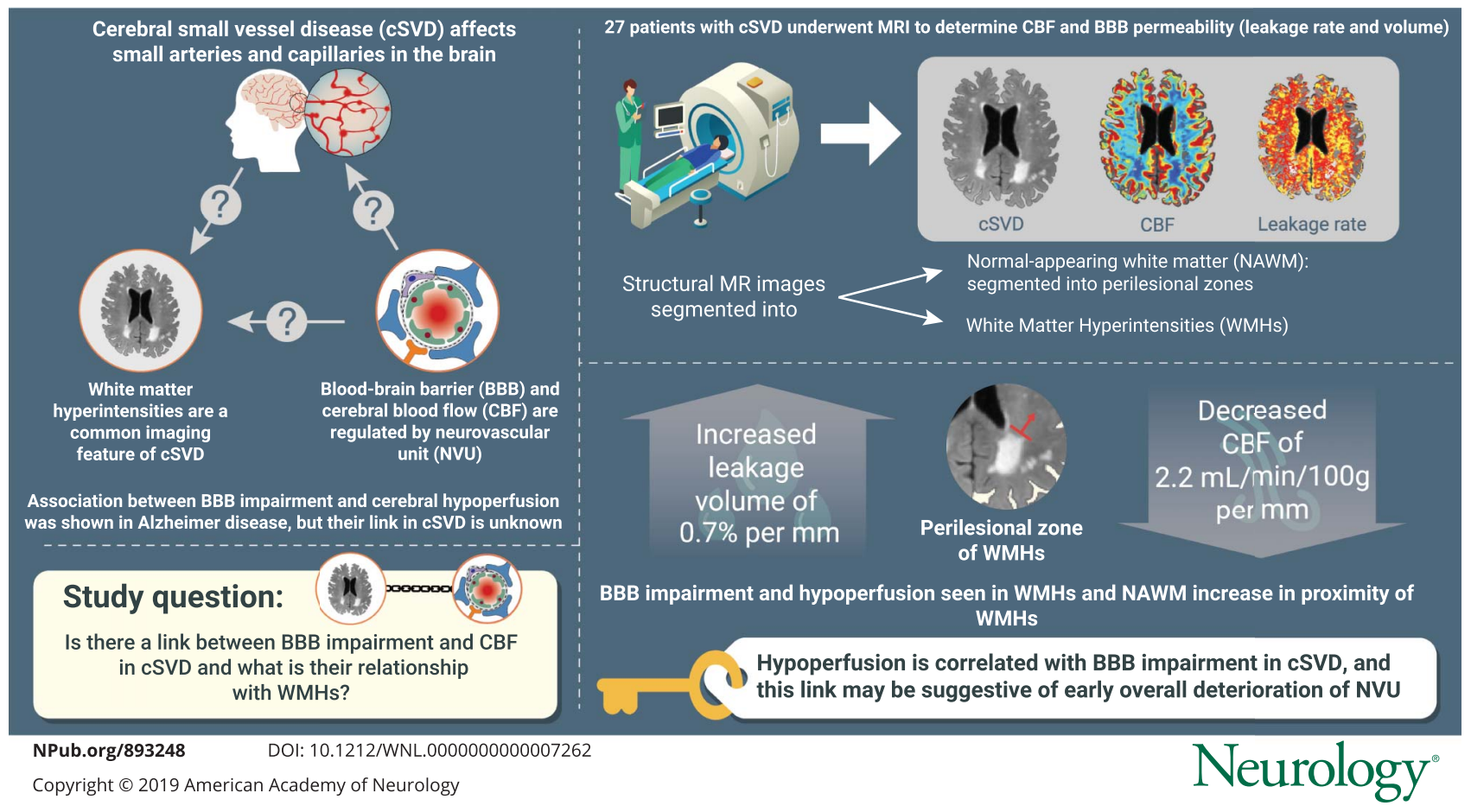

Cerebral small vessel disease (cSVD) affects small arteries, arterioles, venules, and capillaries in the brain. ${ }^{1,2}$ It is an umbrella term covering several pathologies with various etiologies. White matter (WM) alterations observed as WM hyperintensities (WMH) on MRI is a common imaging feature of cSVD. ${ }^{1}$ Several mechanisms have previously been linked to the pathophysiology of $\mathrm{WMH}$ including hypoperfusion ${ }^{3,4}$ and increased permeability of the blood-brain barrier (BBB) ${ }^{5-7}$

Both $\mathrm{BBB}$ permeability and $\mathrm{CBF}$ regulation are functional elements controlled in the neurovascular unit (NVU). ${ }^{8}$ This unit is composed of both neuronal and vascular cells, including endothelial cells, basal lamina, astrocytes and their endfeet, neurons, intervening neurons and their axons, pericytes, and (vascular) smooth muscle cells. ${ }^{8-10}$ One of the main functions of the NVU is neurovascular coupling, in which energy demand of brain activity is ensured by regulating the supply of energetic metabolites, nutrients, and oxygen via the blood circulation. ${ }^{8,10}$

Previously, a correlation between BBB impairment and cerebral hypoperfusion has been demonstrated in Alzheimer disease. ${ }^{11}$ It is unknown whether this relation also exists in cSVD. Therefore, we aimed to determine both BBB permeability and $\mathrm{CBF}$, in terms of leakage and flow of gadolinium contrast agents, respectively, and to study their relationship with $\mathrm{WMH}$ and the perilesional zone in patients with cSVD.

\section{Methods}

\section{Study population}

The study population was obtained from a larger cSVD patient population $(n=77)$ studied earlier for BBB impairment. ${ }^{9}$ These patients either had a first-ever lacunar stroke or were diagnosed with mild vascular cognitive impairment (VCI), which are considered to be the 2 most important clinical manifestations of cSVD most likely due to age- and cardiovascular risk factor-related cSVD. These 2 clinical entities are the most common manifestations of the same underlying small vessel disease although VCI is the chronic manifestation whereas lacunar stroke is acute. ${ }^{10}$ Patients were included in this study between April 2013 and December 2014 from the Maastricht University Medical Centre and 
Zuyderland Medical Centre, the Netherlands. ${ }^{9}$ Specific information on the inclusion can be found in supplemental data e-1 (doi.org/10.5061/dryad.m9c8tn8). From that cohort, we selected all patients who had received both dynamic contrastenhanced (DCE) and dynamic susceptibility contrast (DSC) MRI ( $\mathrm{n}=27,69 \pm 12$ years [mean \pm SD], 63\% male, 54\% hypertensive, $19 \%$ diabetic, $81 \%$ prevalence of hypercholesterolemia, 19\% smokers, average [SD] body mass index 26.4 [4.0]). Definition of specific patient demographics can be found in supplemental data e-2 (doi.org/10.5061/dryad. $\mathrm{m} 9 \mathrm{c} 8 \operatorname{tn} 8)$.

\section{Standard protocol approvals, registrations, and patient consents}

The study was approved by the Medical Ethical Committee of our institution. All participants were included after written informed consent was obtained. This study is registered on trialregister.nl (NTR number NTR3786).

\section{Imaging protocol}

All participants received brain imaging on an MRI system (3T, Achieva TX; Philips Healthcare, Best, the Netherlands) using a 32-element head coil suitable for parallel imaging.

\section{Structural imaging}

A T1-weighted sequence (repetition time $[\mathrm{TR}] /$ inversion time $[\mathrm{TI}] /$ echo time $[\mathrm{TE}]=8.3 / 800 / 3.8 \mathrm{~ms}$; field of view [FOV] $256 \times 256 \times 160 \mathrm{~mm}^{3} ; 1.0 \mathrm{~mm}^{3}$ cubic voxel) was performed to image the anatomy of the cerebrum. To visualize WMH, a T2-weighted fluid-attenuated inversion recovery (FLAIR) sequence $(\mathrm{TR} / \mathrm{TI} / \mathrm{TE}=4.800 / 1.650 / 299$ ms; FOV $250 \times 256 \times 180 \mathrm{~mm}^{3}$; $1.0 \mathrm{~mm}^{3}$ cubic voxel) was used.

\section{DCE-MRI}

Dynamic imaging was performed using dual temporal resolution DCE-MRI sequence, which consisted of 2 integrated saturation recovery gradient recalled sequences mainly differing in dynamic scan interval (DSI) and spatial resolution. ${ }^{11-13}$ The first sequence (DSI 3.2 seconds, TR/TE $=5.6 / 2.5 \mathrm{~ms}$, flip angle $30^{\circ}$, FOV $256 \times 200 \times 50 \mathrm{~mm}^{3}$, voxel size $2 \times 2 \times 5 \mathrm{~mm}^{3}$, SENSE factor 2, 29 image volumes including 9 precontrast volumes, duration 1:33 minutes) was applied during contrast injection (gadobutrol, $0.1 \mathrm{mmol} / \mathrm{kg}$, injected in the antecubital vein, rate $3 \mathrm{~mL} / \mathrm{s}$, followed by a 20 $\mathrm{mL}$ saline flush) to measure the fast signal changes due to the early circulatory phases of the contrast agent. Using the second sequence (DSI 30.5 seconds, TR/TE $=5.6 / 2.5 \mathrm{~ms}$, flip angle $30^{\circ}$, FOV $256 \times 256 \times 100 \mathrm{~mm}^{3}$, voxel size of $1 \times 1 \times$ $2 \mathrm{~mm}^{3}$, SENSE factor 2,45 image volumes including 3 precontrast volumes, duration 22:53 minutes), the slow extravasation of contrast agent in tissue was sampled. Both sequences overlapped spatially with the periventricular regions since it is the most vulnerable region in patients with cSVD. ${ }^{11}$ Before dynamic imaging, T1 mapping of the native brain tissue ${ }^{12}$ was employed to enable the conversion of the contrast-enhanced signal intensity time series to tissue concentrations.

\section{DSC-MRI}

After DCE-MRI, DSC-MRI was performed, which has also been described previously. ${ }^{13}$ Employing settings similar to the DCE-MRI experiments for the injection of the contrast agent, 75 image volumes of the cerebrum were obtained using a 3D gradient echo (principles of echo-shifting with a train of observation [PRESTO]) sequence and the contrast agent was injected at the start of the 11 th time point ${ }^{14}$ (DSI $1.56 \mathrm{sec}-$ onds, TR/TE $20 / 30 \mathrm{~ms}$, flip angle $8^{\circ}$, FOV $240 \times 190 \times$ $105 \mathrm{~mm}^{3}$, voxel size $1.9 \times 1.9 \times 3.5 \mathrm{~mm}^{3}$, duration $1: 57$ minutes).

\section{Image data analysis}

Both DCE and DSC images were corrected for head displacement by aligning the images to a volume image averaged over the precontrast DCE-MRI scans (FSL v5.0 ${ }^{15}$ ). In the following, the calculation of quantitative measures of both DCE-MRI ${ }^{11-13}$ and DSC-MRI ${ }^{11}$ are explained.

\section{DCE-MRI}

Analysis of the DCE-MRI data consists of pharmacokinetic modeling and histogram analysis. Voxel-wise values of $K_{i}$ were calculated using the Patlak graphical approach. ${ }^{16}$ The employed vascular input function was selected in the superior sagittal sinus per participant. Hereafter, a histogram was calculated from all $K_{i}$ values and a noise subtraction method was performed. $^{11,12}$ In short, a noise distribution was calculated based on the negative tail of the $K_{i}$ histogram. Subtraction of the noise distribution resulted in a positive $K_{i}$ histogram, which reflects the detectable leakage rates. The leakage volume $\left(v_{L}\right)$ was calculated by quantifying the remaining area under the histogram curve and the leakage rate $K_{i}$ was calculated as the mean of the noise-corrected histogram including all voxels. Here $v_{L}$ represents the spatial extent of leakage and $K_{i}$ the rate of the leakage.

\section{DSC-MRI}

Cerebral blood flow (CBF) was also calculated in a voxel-wise manner. CBF was calculated by using a block-circulant

Figure 1 Perilesional zones
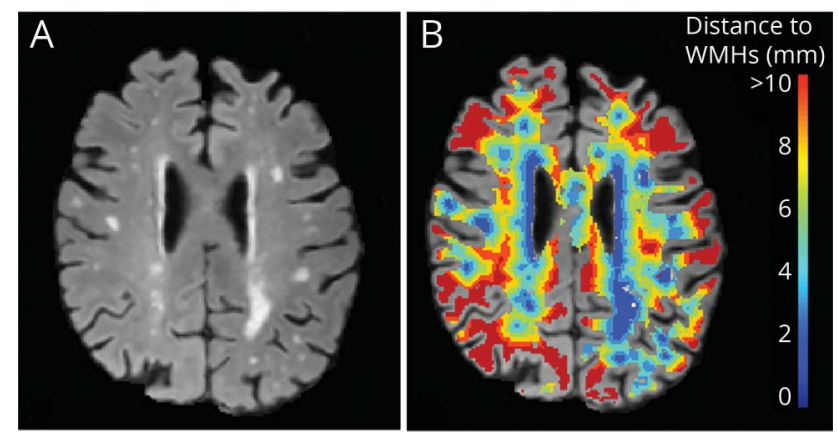

Fluid-attenuated inversion recovery image (A) of a 73-year-old woman with cerebral small vessel disease and a map showing the perilesional zones (B) around white matter hyperintensities (WMHs) (dark blue). 
Table 1 Values of cerebral blood flow (CBF), leakage volume, and leakage rate in cerebral small vessel disease

\begin{tabular}{|c|c|c|c|}
\hline Tissue region & $\mathrm{CBF}, \mathrm{mL} / \mathrm{min} / 100 \mathrm{~g}$, mean $\pm \mathrm{SD}$ & $v_{\mathrm{L},} \%$, mean $\pm S D$ & $K_{\mathrm{i}}\left(\times 10^{-4} \min ^{-1}\right)$, mean $\pm \mathrm{SD}$ \\
\hline NAWM & $80 \pm 19$ & $37 \pm 17$ & $3.5 \pm 1.6$ \\
\hline WMH & $59 \pm 22$ & $43 \pm 20$ & $3.7 \pm 1.8$ \\
\hline GM & $112 \pm 23$ & $23 \pm 15$ & $2.7 \pm 1.3$ \\
\hline
\end{tabular}

Abbreviations: $\mathrm{GM}=$ gray matter; $v_{\mathrm{L}}=$ leakage volume; $K_{\mathrm{i}}=$ leakage rate; $\mathrm{NAWM}=$ normal-appearing white matter; $\mathrm{WMH}=$ white matter hyperintensities.

singular value decomposition algorithm, in which singular values below $10 \%$ of the maximal singular value were set to zero. ${ }^{17,18}$ The arterial input function employed for the flow assessment was derived from the anterior cerebral artery. To exclude contamination of large blood vessels, voxels with cerebral blood values $>10 \%$ were excluded from the analysis. ${ }^{19}$

\section{Regions of interest (ROIs) analysis and measures}

T1-weighted images and FLAIR images were coregistered to the averaged precontrast DCE-MRI scans. Subsequently, WM was segmented from the gray matter (GM) using Freesurfer ${ }^{20}$ and the $\mathrm{WMH}$ were segmented from normal-appearing $\mathrm{WM}$ (NAWM) using a semi-automated method ${ }^{21}$ followed by visual checks under supervision of vascular neurologists (J.S. and R.J.v.O.). This resulted in 3 tissue ROIs: the NAWM, $\mathrm{WMH}$, and GM, which consisted of the basal ganglia and cortex. For spatial analysis, the NAWM was divided into a number of perilesional zones by segmenting 5 shells with 2 - $\mathrm{mm}$ width using a dilation operation of $2 \mathrm{~mm}$ around the WMH (figure 1). For all ROIs, the $K_{i}, v_{L}$, and the mean value of $\mathrm{CBF}$ were calculated. The coupling (i.e., regression) coefficient $\alpha$ was defined as the regression slope between the leakage measures and $\mathrm{CBF}$ and was calculated per shell.

\section{Statistical analysis}

The absolute values of the leakage measures $\left(K_{i}\right.$ and $\left.v_{L}\right)$ and $\mathrm{CBF}$ values over the shells were assessed using regression analysis. Furthermore, the relation between the leakage measures and CBF was studied by calculating both the Pearson correlation coefficient $(r)$ and the coupling coefficient $\alpha$ and was adjusted for age and sex. All correlation analyses were performed for the NAWM, GM, and WMH. In case a significant correlation between leakage measures and CBF was observed in the NAWM, the coupling coefficient a was investigated as a function of distance to the WMH using linear regression. Significance was inferred for $p<0.050$. All statistical analyses were performed using commercial software (SPSS, version 22, IBM, Armonk, NY).

\section{Data availability}

On request via the corresponding author, the identified summary data used in this study will be shared with other researchers.

\section{Results}

We present mean values over all patients of the CBF, the leakage volume $v_{L}$, and leakage rate $K_{i}$ for all ROIs in table 1 and an example of maps with values for $\mathrm{CBF}$ and leakage rate $K_{i}$ for a patient with cSVD in figure 2 . In figure 3 , mean values of $\mathrm{CBF}$, the leakage volume $v_{L}$, and leakage rate $K_{i}$ are presented for the perilesional zones.

\section{Leakage measures}

Leakage volumes $v_{L}$ were higher in WMH than in NAWM (mean $[95 \%$ confidence interval $(\mathrm{CI})] 6.5[1.3,11.7] \%, p=$ 0.016 ) and higher in the WM than in the GM (NAWM: 14.2 $[11.1,17.2] \%, p<0.001$; WMH: $20.7[15.3,26.0] \%$, $p<0.001$ ) (table 1). Higher leakage rates were observed in the WM than in the GM (NAWM: $0.8[0.4,1.1] \times 10^{-4} \mathrm{~min}^{-1}$, $p<0.010$; WMH: $1.0[0.5,1.5] \times 10^{-4} \mathrm{~min}^{-1}, p<0.010$ ) (table 1). In the perilesional zones of $\mathrm{WMH}$, a relation between the leakage

Figure 2 Maps of the cerebral blood flow and leakage rate
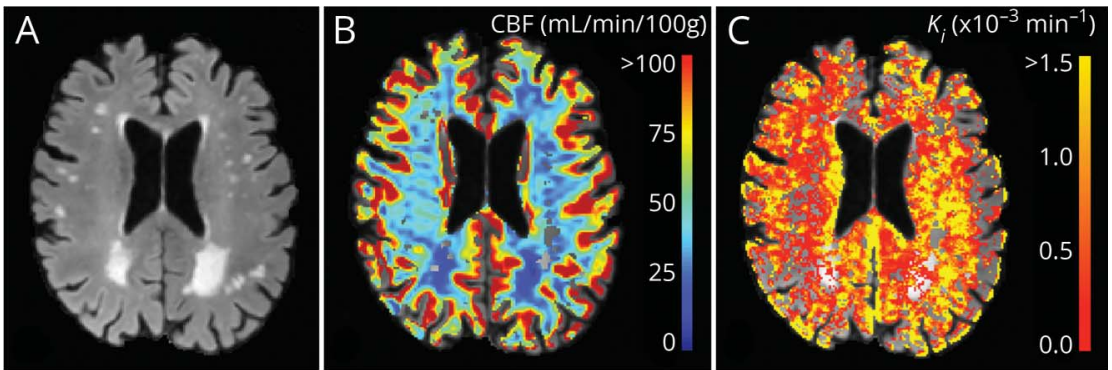

Fluid-attenuated inversion recovery image $(A)$ of a 73-year-old woman with cerebral small vessel disease and maps with values for cerebral blood flow (CBF) (B) and leakage rate $K_{\mathrm{i}}(\mathrm{C})$. 
Figure 3 Cerebral blood flow (CBF), leakage volume, and leakage rate for the white matter hyperintensities $(\mathrm{WMH})$ and perilesional zones

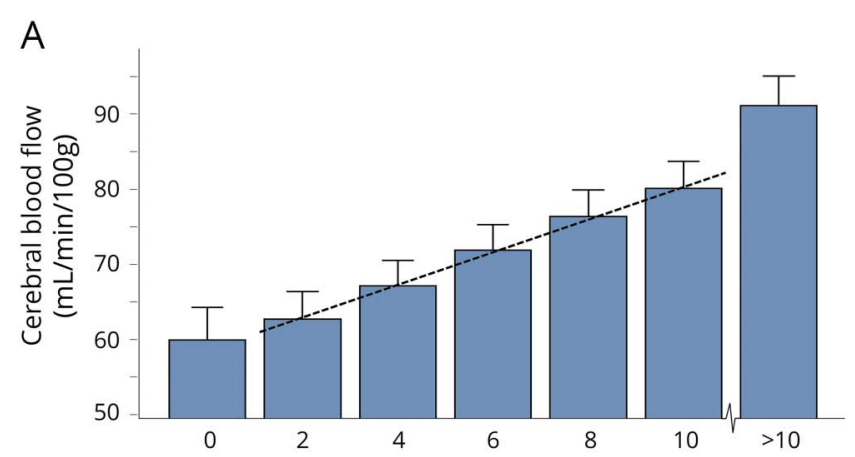

$\mathrm{B}$

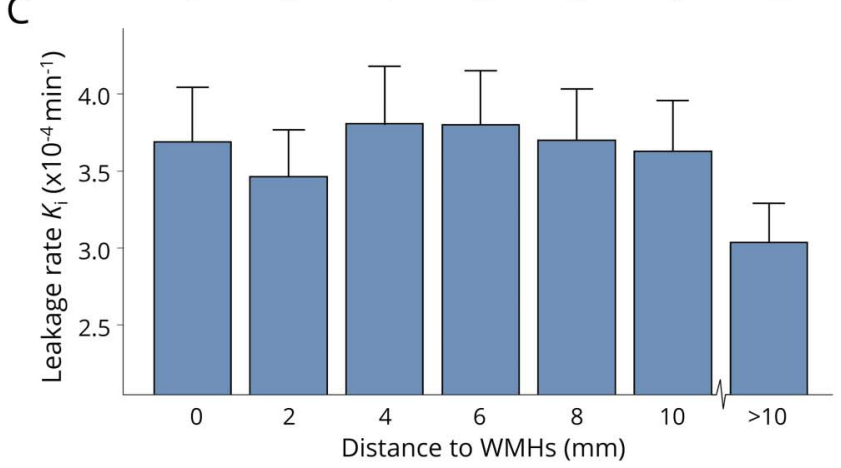

(A) $\mathrm{CBF}$, (B) leakage volume, and (C) leakage rate for the $\mathrm{WMH}$ (i.e., $0 \mathrm{~mm}$ ) and perilesional zones in the normal-appearing white matter with increasing distance to the $\mathrm{WMH}$. Corresponding regression lines of the average values per perilesional zone are plotted. CBF values increased $(y=58.5+$ $2.2 \mathrm{x}, p<0.01)$ and leakage volumes decreased linearly $(\mathrm{y}=46.1-0.7 \mathrm{x}, p<$ 0.01 ) with increasing distance from the $\mathrm{WMH}$. No significant linear relation was observed for the leakage rate over the perilesional zones ( $p=0.69)$, though it also decreased at larger distance.

volumes, but not the leakage rates, was observed: the leakage volume increases with $0.7 \%$ (95\% CI $1.0 \%, 0.4 \%, p<0.01$ ) per mm closer to the outer boundary of WMH (figure 3 ).

\section{Cerebral blood flow}

CBF in the WMH was lower than in the NAWM (mean [95\% CI $]-20.4[-25.2,-15.6] \mathrm{mL} / \mathrm{min} / 100 \mathrm{~g}, p<0.001)$. In the WM, CBF was lower than in the GM (NAWM: $-32.2[-35.8$, $28.6] \mathrm{mL} / \mathrm{min} / 100 \mathrm{~g}, p<0.001$, WMH: $-52.6[-57.4,-47.8]$, $p<0.001$ ) (table 2). In the perilesional zones, the CBF value decreased with 2.2 (95\% CI 2.0, 2.4, $p<0.01$ ) $\mathrm{mL} / \mathrm{min} /$ $100 \mathrm{~g}$ per $\mathrm{mm}$ closer to the outer boundaries from $\mathrm{WMH}$ (figure 3).

\section{Relation between CBF and BBB permeability}

Table 2 shows the Pearson correlation coefficient $r$ and the coupling coefficient $\alpha$ for the leakage measures and CBF for various regions in the brain. Larger leakage volumes $v_{L}$ were associated with lower $\mathrm{CBF}$ in the NAWM and WMH (figure 4). Higher leakage rates $K_{i}$ were correlated with lower CBF in the NAWM and WMH (figure 4).

For the perilesional zones of the $\mathrm{WMH}$, a similar relation of larger leakage volumes $v_{L}$ and higher leakage rates $K_{i}$ with lower CBF was observed as found in the NAWM. The strength of the coupling coefficient $\alpha$ between the leakage rate $K_{i}$ and $\mathrm{CBF}$ increased with $0.17 \times 10^{-6} 1 /(\mathrm{mL} \times 100 \mathrm{~g})(p=$ 0.03 ) per mm closer to the WMH. No relation of the coupling coefficients $\alpha$ between the leakage volume $v_{L}$ and CBF were observed.

\section{Discussion}

In the present study on patients with manifest cSVD, we investigated the permeability of the $\mathrm{BBB}$ and $\mathrm{CBF}$ as well as their relation. We showed that $\mathrm{BBB}$ impairment and lower $\mathrm{CBF}$ were strongest in or close to the $\mathrm{WMH}$, and became less prominent at greater distance from the $\mathrm{WMH}$. We also revealed a negative relation between increased BBB impairment, in terms of both increased leakage rate and volume, and lower CBF in both NAWM as well as WMH. This relation was strongest in tissue regions close to the $\mathrm{WMH}$.

In the $\mathrm{WMH}$, stronger leakage rates and volumes were observed than in the NAWM and GM. Leakage volumes appeared to be largest in the proximity of the WMH. This is in concordance with an increase in abnormal BBB permeability towards the $\mathrm{WMH}$ observed in previous studies ${ }^{22,23}$ and implies that the BBB in NAWM is increasingly impaired in the proximity of WMH. Expansion of WMH has been suggested to proceed at its borders. ${ }^{24,25}$ Altogether this suggests that $\mathrm{BBB}$ impairment may occur prior to the formation of $\mathrm{WMH}$. This thought fits the hypothesis that a more leaky BBB results in WM damage involving perivascular edema ${ }^{6,7,26,27}$; a more permeable BBB can lead to accumulation of bloodborne products causing perivascular edema, which can intoxicate brain cells and ultimately leads to demyelination as observed in $\mathrm{WMH}^{7,26,27}$

CBF values of the WMH were on average $26 \%$ lower than of the NAWM, which demonstrated the hypoperfusion in the lesions. This agrees with a study also using DSC-MRI in patients with leukoaraiosis. ${ }^{28} \mathrm{We}$ also showed a decrease of the $\mathrm{CBF}$ in the perilesional zone, which more or less normalized at more distant regions from the outer boundaries of WMH. Thus, even in normal-appearing tissue in cSVD, the physiology is deviant in the proximity of WMH. This is in accordance with a longitudinal study showing low CBF preceding WMH formation. ${ }^{3}$ The impairment of $\mathrm{CBF}$ regulation involves a plausible pathophysiologic sequence through changes of the vessel wall structure of microvessels including 
Table 2 Relation between the leakage measures and cerebral blood flow for the NAWM, WMH, GM and the perilesional zones

\begin{tabular}{|c|c|c|c|}
\hline & Pearson correlation $(\mathrm{Cl})$ & Coupling coefficient $(\mathrm{Cl})^{a}$ & $p$ Value \\
\hline \multicolumn{4}{|c|}{ Leakage volume $v_{\mathrm{L}}$} \\
\hline NAWM & -0.40 & $-3.4(-6.8,-0.1)$ & 0.045 \\
\hline WMH & -0.53 & $-4.6(-8.3,-0.9)$ & 0.016 \\
\hline GM & -0.36 & $-2.2(-4.8,0.4)$ & 0.094 \\
\hline \multicolumn{4}{|c|}{ Perilesional zones (distance to WMH, mm) } \\
\hline 2 & $-0,45$ & $-4.9(-8.8,-1,1)$ & 0.015 \\
\hline 4 & -0.40 & $-4.5(-8.5,-0.5)$ & 0.030 \\
\hline 6 & -0.35 & $-3.8(-7.7,0.2)$ & 0.063 \\
\hline 8 & -0.37 & $-3.7(-7.4,0,0)$ & 0.052 \\
\hline 10 & -0.42 & $-4.0(-7.4,-0.5)$ & 0.027 \\
\hline \multicolumn{4}{|c|}{ Leakage rate $K_{i}$} \\
\hline NAWM & -0.41 & $-3.0(-6.0,0.0)$ & 0.033 \\
\hline WMH & -0.48 & $-3.9(-6.9,0.0)$ & 0.030 \\
\hline GM & -0.37 & $-2.0(-4.0,0.0)$ & 0.077 \\
\hline \multicolumn{4}{|c|}{ Perilesional zones (distance to $\mathrm{WMH}, \mathrm{mm}$ ) } \\
\hline 2 & -0.46 & $-5.0(-9.0,-1.0)$ & 0.017 \\
\hline 4 & -0.44 & $-5.0(-9.0,-1.0)$ & 0.019 \\
\hline 6 & -0.42 & $-4.0(-8.0,-1.0)$ & 0.026 \\
\hline 8 & -0.39 & $-4.0(-7.0,-0.0)$ & 0.034 \\
\hline 10 & -0.40 & $-4.0(-7.0,-0.0)$ & 0.030 \\
\hline
\end{tabular}

Abbreviations: $\mathrm{Cl}$ = confidence interval; $\mathrm{GM}=$ gray matter; $\mathrm{NAWM}=$ normal-appearing white matter; $\mathrm{WMH}$ = white matter hyperintensities .

a Units: $v_{\mathrm{L}}: \times 10^{-3} \% /(\mathrm{mL} / \mathrm{min} / 100 \mathrm{~g}) ; K_{\mathrm{i}}: \times 10^{-6} \mathrm{~mL}^{-1} \cdot 100 \mathrm{~g}^{-1}$.

narrowing of the arteriolar lumen and thickening of the vessel wall by fibro-hyaline material. ${ }^{4,26,29}$ These structural changes in the vessel wall can impair hemodynamics, through influencing contraction and dilation of vessels, and can lead to ischemia in the most distal vascular territories. ${ }^{29}$ These regions are most vulnerable for impairment of blood supply and are likely to be at risk for structural brain damage. ${ }^{4}$

In the present study, we found that both leakage measures (i.e., leakage volume and rate) were negatively related with lower CBF in all tissue regions; stronger leakage values were linked with lower CBF. This link became weaker in the perilesional zones at larger distances from the $\mathrm{WMH}$. In the following, several suggestions are offered to explain the results found in the current study.

Purely considering the blood vessels (i.e., without a regulatory mechanism and with subtle BBB defects) in healthy aging, a positive relation would have been expected, as a decreased CBF would give rise to less supply of contrast material and consequently less leaking contrast molecules. We propose several mechanisms that may explain the negative relation between BBB leakage and lower CBF. First, a lower shear stress, which can result from lower $\mathrm{CBF}$, has been shown to contribute to lower expression of tight junctions hence leading to a more permeable BBB. ${ }^{30}$ Second, it has been suggested that hypoxia, which can also result from lower $\mathrm{CBF}$, induces the activation of several mechanisms including the increase of $\mathrm{BBB}$ permeability ${ }^{8}$ to prevent tissue damage.

Our study demonstrates a link between BBB impairment and lower $\mathrm{CBF}$, but whether they are causally related, and in which direction, cannot be concluded. Nevertheless it suggests that both are involved in the pathophysiology of cSVD. Both BBB and $\mathrm{CBF}$ are regulated by the NVU. The link between $\mathrm{BBB}$ impairment and lower CBF suggests that the defect of one functional element of the NVU can affect other NVU elements. This points at an early overall impairment of the NVU in CSVD and is in agreement with other studies showing that multiple elements of the NVU, including degeneration of the extracellular matrix, ${ }^{31}$ vascular smooth muscle cells, and pericytes, ${ }^{32,33}$ are disrupted in cSVD. Moreover, based on the 

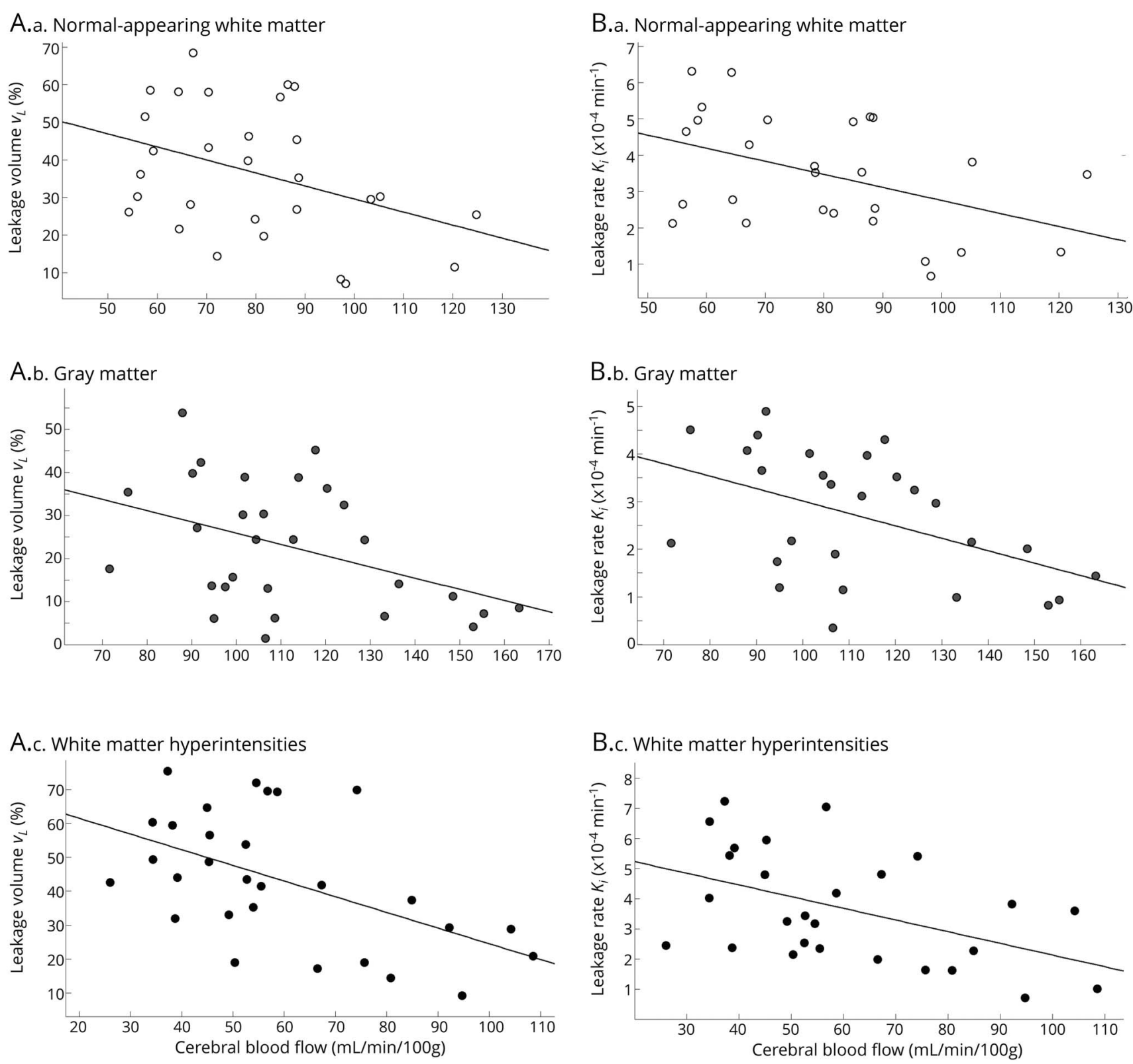

Scatterplot between CBF and leakage volume (A.a-A.C) and CBF and leakage rate (B.a-B.c) with corresponding (unadjusted) regression line. Significant negative correlations were observed between $C B F$ and the leakage volume for the normal-appearing white matter $\left(y=0.65-3.5 \times 10^{-3} x, p=0.05\right)(A . a)$ and white matter hyperintensities $\left(y=0.71-4.6 \times 10^{-3} x, p=0.02\right)$ (A.C). A similar relation (but not significant) between reduced CBF and increased leakage volume in the gray matter was observed ( $y=0.52-2.6 \times 10^{-3} \times p=0.09$ ) (A.b). Significant negative correlations were also observed between CBF and leakage rate for the normal-appearing white matter $\left(y=0.64-3.6 \times 10^{-6} x, p=0.03\right)$ (B.a) and white matter hyperintensities $\left(y=0.60-3.96 \times 10^{-6} x, p=0.03\right)(B . c)$. A comparable relation (but not significant) between lower CBF and higher leakage rate was observed in the gray matter $\left(y=0.56-2.6 \times 10^{-6} x, p=0.08\right)(B . b)$.

increasing strength of the link between BBB impairment and lower $\mathrm{CBF}$ with closer distance to the $\mathrm{WMH}$, we suggest that NVU impairment may be related to structural damage in the WM. Recent studies have also proposed a similar view implying that impairment of the NVU is a pathologic loop ultimately leading to a cascade of damage including WM injury. ${ }^{8,29}$ Future studies should investigate the highly complex mechanisms in the NVU and study the BBB permeability and hypoperfusion in a longitudinal fashion to further establish their link and tell us more about a causal direction.
Future interventions could aim to counteract functional loss in CSVD to preserve the WM. Moreover, BBB and CBF measures can be employed as quantitative imaging biomarkers to monitor the effectiveness of these interventions. It is also shown that $\mathrm{BBB}$ impairment and lower $\mathrm{CBF}$ are related in WM degeneration possibly in the context of early overall NVU impairment.

More studies are needed to establish the exact link between BBB impairment and lower CBF. Nevertheless, this link may 
imply that targeting either one (i.e., BBB impairment or hypoperfusion) for treatment of CSVD could be done indirectly; for example, stabilization of the BBB may lie in the better control of the vascular condition by controlling the vascular risk factors, for example hypertension, by using antihypertensive drugs ${ }^{34}$ or smoking cessation. ${ }^{35}$

For this study, a dedicated technique to measure subtle leakage was employed. The DCE-MRI sequence includes a fast and a slow sequence to measure the wash-in of the contrast agent, to accurately sample the vascular input function, and the slow extravasation of contrast agent in tissue, respectively. Another strength of our study is that a spatial perilesional analysis was performed that showed regional differences around $\mathrm{WMH}$.

Our study also has limitations. First, this study is an explorative study and therefore the study population is not large. Consequently, our results should be interpreted with caution. Nevertheless, this study shows promising results in investigating the possible relation between $\mathrm{BBB}$ impairment and diminished blood flow using MRI. Future studies investigating the link between both mechanisms should include more participants. Second, for the contrast-enhanced techniques, different blood vessels were used to select the vascular input function, as for each technique the best option was selected. The effect of different vascular input functions on the link between $\mathrm{BBB}$ permeability and $\mathrm{CBF}$ should be studied in more detail. Third, the observed CBF values for the current study population seem to be higher than those found in the literature. Possibly this is caused by a different measurement or analysis method that was used to determine absolute values of CBF. However, we used the method as described in a study by van de Haar et al., ${ }^{13}$ to which our results compare well. Furthermore, we performed the same method for the entire study population and the derived correlations are not dependent on the magnitude of the $\mathrm{CBF}$ values. Fourth, the determination of the coupling coefficient $\alpha$ was based on regression analysis between leakage measures and CBF over multiple participants, which yielded that participants with lower CBF exhibit stronger BBB impairment. The observed link suggests the involvement of a physiologic regulation mechanism of the NVU to compensate for oxygen or metabolite deficiency. However, whether BBB permeability and hypoperfusion are truly dynamically coupled in the same participant is not yet proven from this study and requires a longitudinal setup. Finally, because we have selected patients with cognitive impairment, some patients might have some early Alzheimer pathology, which may have confounded our results. However, we strove to exclude patients with $\mathrm{Alz}$ heimer disease as much as possible based on extensive neuropsychological assessment, evaluation of patient history, and screening volumetric MRI abnormalities (i.e., evident hippocampal atrophy).

We demonstrated functional loss of the cerebral microvasculature in terms of $\mathrm{BBB}$ impairment and cerebral hypoperfusion, and their link in the WM and the perilesional zones of the WMH. This link may indicate early overall deterioration of the NVU. Future investigation into WM degeneration in CSVD should consider the failure of multiple mechanisms in the context of NVU impairment.

\section{Author contributions}

S.M. Wong: drafting/revising the manuscript, data acquisition, study concept or design, analysis or interpretation of data, accepts responsibility for conduct of research and final approval, acquisition of data, statistical analysis. J.F.A. Jansen: drafting/revising the manuscript, data acquisition, study concept or design, analysis or interpretation of data, accepts responsibility for conduct of research and final approval, obtaining funding. E. Zhang: data acquisition, accepts responsibility for conduct of research and final approval. E. Hoff: drafting/revising the manuscript, accepts responsibility for conduct of research and final approval, acquisition of data. J. Staals: drafting/revising the manuscript, accepts responsibility for conduct of research and final approval, study supervision. R. van Oostenbrugge: study concept or design, analysis or interpretation of data, accepts responsibility for conduct of research and final approval, study supervision, obtaining funding. W.H. Backes: drafting/ revising the manuscript, data acquisition, study concept or design, analysis or interpretation of data, accepts responsibility for conduct of research and final approval, acquisition of data, statistical analysis, study supervision, obtaining funding.

\section{Study funding}

This project has received funding from NWO (Netherlands Organization for Scientific Research, grant: 017.009.048), the European Union's Horizon 2020 research and innovation program (grant: 666881, SVDs@target), Hersenstichting (grant: 2013[1]-195), and Stichting de Weijerhorst Foundation.

\section{Disclosure}

The authors report no disclosures relevant to the manuscript. Go to Neurology.org/ $\mathrm{N}$ for full disclosures.

\section{Publication history}

Received by Neurology March 21, 2018. Accepted in final form November 28, 2018.

\section{References}

1. Wardlaw JM, Smith EE, Biessels GJ, et al. Neuroimaging standards for research into small vessel disease and its contribution to ageing and neurodegeneration. Lancet Neurol 2013;12:822-838

2. Pantoni L. Definition and classification of small vessel disease. In: Pantoni L, Gorelick PB, eds. Cerebral Small Vessel Disease, 1st ed. Cambridge: Cambridge University Press; 2014:1-3.

3. ten Dam VH, van den Heuvel DM, de Craen AJ, et al. Decline in total cerebral blood flow is linked with increase in periventricular but not deep white matter hyperintensities. Radiology 2007;243:198-203.

4. Pantoni L, Garcia JH. Pathogenesis of leukoaraiosis: a review. Stroke 1997;28: 652-659.

5. Wardlaw JM, Smith C. Mechanisms underlying sporadic cerebral small vessel disease: insights from neuroimaging. Lancet Neurol 2013;12:483-497.

6. Rosenberg GA, Sullivan N, Esiri MM. White matter damage is associated with matrix metalloproteinases in vascular dementia. Stroke 2001;32:1162-1168. 
7. Lammie GA, Brannan F, Wardlaw JM. Incomplete lacunar infarction (type Ib lacunes). Acta Neuropathol 1998;96:163-171.

8. Stanimirovic DB, Friedman A. Pathophysiology of the neurovascular unit: disease cause or consequence? J Cereb Blood Flow Metab 2012;32:1207-1221.

9. Zhang CE, Wong SM, van de Haar HJ, et al. Blood-brain barrier leakage is more widespread in patients with cerebral small vessel disease. Neurology 2017;88:426-432.

10. Pantoni L. Cerebral small vessel disease: from pathogenesis and clinical characteristics to therapeutic challenges. Lancet Neurol 2010;9:689-701.

11. Duering M, Csanadi E, Gesierich B, et al. Incident lacunes preferentially localize to the edge of white matter hyperintensities: insights into the pathophysiology of cerebral small vessel disease. Brain 2013;136:2717-2726.

12. Larsson HBW, Courivaud F, Rostrup E, Hansen AE. Measurement of brain perfusion, blood volume, and blood-brain barrier permeability, using dynamic contrastenhanced T1-weighted MRI at 3 tesla. Magn Reson Med 2009;62:1270-1281.

13. van de Haar HJ, Burgmans S, Jansen JFA, et al. Blood-brain barrier leakage in patients with early Alzheimer disease. Radiology 2016;281:527-535.

14. Liu G, Sobering G, Duyn J, Moonen CT. A functional MRI technique combining principles of echo-shifting with a train of observations (PRESTO). Magn Reson Med 1993;30:764-768.

15. Jenkinson M, Bannister P, Brady M, Smith S. Improved optimization for the robust and accurate linear registration and motion correction of brain images. Neuroimage 2002;17:825-841.

16. Patlak CS, Blasberg RG, Fenstermacher JD. Graphical evaluation of blood-to-brain transfer constants from multiple-time uptake data. J Cereb Blood Flow Metab 1983;3:1-7.

17. Wu O, Østergaard L, Weisskoff RM, Benner T, Rosen BR, Sorensen AG. Tracer arrival timing-insensitive technique for estimating flow in MR perfusion-weighted imaging using singular value decomposition with a block-circulant deconvolution matrix. Magn Reson Med 2003;50:164-174.

18. Willats L, Calamante F. The 39 steps: evading error and deciphering the secrets for accurate dynamic susceptibility contrast MRI. NMR Biomed 2013;26:913-931.

19. Knutsson L, Lindgren E, Ahlgren A, et al. Dynamic susceptibility contrast MRI with a prebolus contrast agent administration design for improved absolute quantification of perfusion. Magn Reson Med 2014;72:996-1006.

20. Fischl B, Salat DH, Busa E, et al. Whole brain segmentation: automated labeling of neuroanatomical structures in the human brain. Neuron 2002;33:341-355.

21. de Boer R, Vrooman H, van der Lijn F, et al. White matter lesion extension to automatic brain tissue segmentation on MRI. Neuroimage 2009;45:1151-1161.
22. Wardlaw JM, Makin S, Valdés Hernández MC, et al. Blood-brain barrier failure as a core mechanism in cerebral small vessel disease and dementia: evidence from a cohort study. Alzheimers Dement 2017;13:634-643.

23. Huisa BN, Caprihan A, Thompson J, Prestopnik J, Qualls CR, Rosenberg GA. Longterm blood-brain barrier permeability changes in Binswanger disease. Stroke 2015; 46:2413-2418.

24. Maillard P, Carmichael O, Fletcher E, Reed B, Mungas D, DeCarli C. Coevolution of white matter hyperintensities and cognition in the elderly. Neurology 2012;79: $442-448$.

25. Lambert C, Benjamin P, Zeestraten EA, Lawrence AJ, Barrick TR, Markus HS Longitudinal patterns of leukoaraiosis and brain atrophy in symptomatic small vessel disease. Brain 2016;139:1136-1151.

26. Wardlaw JM, Pantoni L. Sporadic small vessel disease: pathogenic aspects. In: Pantoni L, Gorelick P, eds. Cerebral Small Vessel Disease, 1st ed. Cambridge: Cambridge University Press; 2014:52-63.

27. Rosenberg GA, Wallin A, Wardlaw JM, et al. Consensus statement for diagnosis of subcortical small vessel disease. J Cereb Blood Flow Metab 2016;36:6-25.

28. O'Sullivan M, Lythgoe DJ, Pereira C, et al. Patterns of cerebral blood flow reduction in patients with ischemic leukoaraiosis. Neurology 2002;59:321-326.

29. Kisler K, Nelson AR, Montagne A, Zlokovic BV. Cerebral blood flow regulation and neurovascular dysfunction in Alzheimer disease. Nat Rev Neurosci 2017;18:419-434.

30. Cucullo L, Hossain M, Puvenna V, Marchi N, Janigro D. The role of shear stress in blood-brain barrier endothelial physiology. BMC Neurosci 2011;12:40.

31. del Zoppo GJ. The neurovascular unit, matrix proteases, and innate inflammation. Ann NY Acad Sci 2010;1207:46-49.

32. Ghosh M, Balbi M, Hellal F, Dichgans M, Lindauer U, Plesnila N. Pericytes are involved in the pathogenesis of cerebral autosomal dominant arteriopathy with subcortical infarcts and leukoencephalopathy. Ann Neurol 2015;78:887-900.

33. Joutel A, Monet-Leprêtre M, Gosele C, et al. Cerebrovascular dysfunction and microcirculation rarefaction precede white matter lesions in a mouse genetic model of cerebral ischemic small vessel disease. J Clin Invest 2010;120:433-445.

34. Iadecola C, Yaffe K, Biller J, et al. Impact of hypertension on cognitive function: a scientific statement from the American heart association. Hypertension 2016;68: e67-e94.

35. Staals J, Makin SDJ, Doubal FN, Dennis MS, Wardlaw JM. Stroke subtype, vascular risk factors, and total MRI brain small-vessel disease burden. Neurology 2014;84: $1228-1235$ 